Document downloaded from:

http://hdl.handle.net/10251/169178

This paper must be cited as:

Bermúdez, V.; Macian Martinez, V.; Villalta-Lara, D.; Soto, L. (2020). Impact of injection settings on gaseous emissions and particle size distribution in the dual-mode dual-fuel concept. International Journal of Engine Research. 21(4):561-577.

https://doi.org/10.1177/1468087419844413

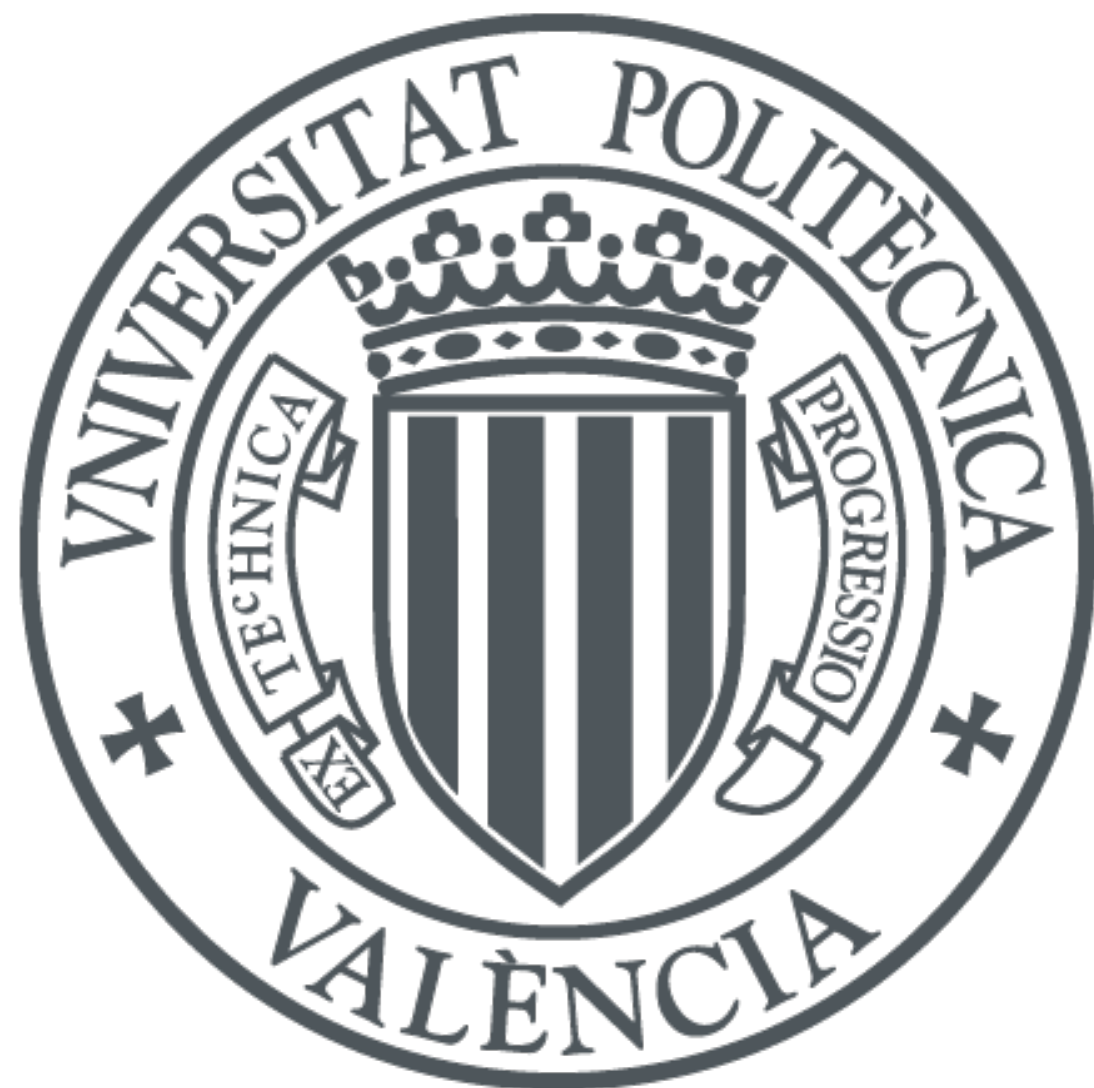

The final publication is available at

https://doi.org/10.1177/1468087419844413

Copyright SAGE Publications

Additional Information

This is the author's version of a work that was accepted for publication in International Journal of Engine Research. Changes resulting from the publishing process, such as peer review, editing, corrections, structural formatting, and other quality control mechanisms may not be reflected in this document. Changes may have been made to this work since it was submitted for publication. A definitive version was subsequently published as https://doi.org/10.1177/1468087419844413. 


\title{
Impact of injection settings on gaseous emissions and particle size distribution in the dual-mode dual-fuel (DMDF) concept
}

\author{
Vicente Bermúdez*, Vicente Macián, David Villalta and Lian Soto \\ Universitat Politècnica de València, CMT-Motores Térmicos, Camino de Vera s/n, 46022 Valencia, Spain. \\ *Corresponding author. Tel.: +34 96387-9652; E-mail: bermudez@mot.upv.es
}

\begin{abstract}
Reactivity Controlled Compression Ignition (RCCI) concept has been highlighted among the low temperature combustion strategies. However, this combustion strategy presents some problems related to high levels of HC and CO emissions at low load and high-pressure rise rate at high load. Therefore, to diminish these limitations, the Dual-mode Dual-fuel (DMDF) concept has been presented as an excellent alternative. This concept uses two fuels of different reactivity and switches from a dual-fuel fully premixed strategy (based on the RCCI concept) during low load to a diffusive nature during high load operation. However, the success of DMDF concept depends to a large extent on the low reactivity/high reactivity fuel ratio and the injection settings. In this study, parametric variations of injection pressure and injection timing were experimentally performed to analyze the effect over each combustion process that encompasses the DMDF concept and its consequent impact on gaseous and particles emissions, including an analysis of particle size distribution. The experimental results confirm how the use of an adequate injection strategy is indispensable to obtain low exhaust emission and a balance between the different pollutants. In the fully premixed RCCI strategy, the particles concentrations were dominated by nucleation-mode, however the increase in injection pressure and the advance of the diesel main injection timing provided a simultaneous reduction of NOx and solid particles (accumulation-mode). During the highly premixed RCCI strategy, the accumulation-mode particles increased, and their concentrations were higher when the diesel main injection timing advanced and injection pressure decreased, as well as there was a slight increase in NOx emissions. Finally, in the dual-fuel diffusion strategy, the concentrations of accumulation-mode particles were higher and there was a considerable increase of these particles with the advance of the diesel main injection timing and the reduction of the injection pressure, while the NOx emissions decreased.
\end{abstract}

Keywords: Dual-fuel combustion, Reactivity controlled compression ignition, Injection strategy, Gaseous emissions and Particle size distribution

\section{Introduction}

Due to increasing social awareness about human health and the environment, the regulations in charge of the limits for the emissions produced by internal combustion engines (ICEs) have evolved significantly. In this context, fuel consumption and the maximum limits of the more harmful pollutants (NOx, HC, CO and PM) have drastically decreased over the last decade. In this context, compression ignition (CI) engines are considered one of the first sources of environmental pollution. The conventional CI engines are well known for their higher thermal efficiency compared to gasoline spark ignition (SI) engines. However, in spite of offering improved fuel economy, it is the characteristic mixing-controlled combustion process of the conventional diesel combustion (CDC) concept, which represents an important source of nitrogen oxides (NOx) and particulate matter (PM) emissions. ${ }^{1,2}$

Different approaches have been explored in the past decade to resolve this natural disadvantage of the CDC concept. From one side, exploring advanced combustion strategies which aim to decrease in-cylinder pollutant formation; and on the other side, the use of external or passive after-treatment systems to reduce engine exhaust emissions. Many of these advanced combustion strategies can be classified as low temperature combustion 
(LTC) concepts which strive for a low combustion temperature or/and increased degree of premixing prior to combustion, to reduce NOx and PM formation. This achievement is possible due to the use of high exhaust gas recirculation (EGR) rates and an adequate adjustment of the injection parameters to achieve longer mixing times comparing with the CDC strategy, which lead to lower combustion temperatures and restraint of local rich fuel equivalence ratios. ${ }^{3,4}$ In addition, LTC characterizes by breaking the trade-off existing in CDC mode while thermal efficiency is maintained or even improved. Thus, thermal efficiency is improved due to the fast heat release of the combustion process and the reduction of the heat transfer because of the lower in-cylinder pressure peak.

A few examples of the numerous explored premixed LTC concepts are homogeneous charge compression ignition (HCCI), premixed charge compression ignition (PCCI), reactivity controlled compression ignition (RCCI) and partially premixed combustion (PPC). Even when the potential for simultaneous reduction of NOx and PM has been already confirmed; there are still many issues to be resolved before adopting these technologies widespread, especially in terms of limited load/speed operating range. The HCCI concept consists of having a basically homogeneous mixture prior to ignition. This is usually achieved by injecting the fuel at the intake system or directly into the cylinder, very early during the compression stroke. ${ }^{5,6}$ This combustion process provides a stabilized flame front, which reduces the combustion temperature and thereby, mitigates the NOx formation. In addition, due to the premixing of the air/fuel, lower local fuel equivalence ratios are achieved which avoids particles formation. However, under these conditions. the start of combustion (SoC) is not triggered by the injection event, but by the chemical kinetics. In such cases, the high tendency to auto-ignition of diesel fuels, characterized by a high cetane number, difficult the combustion phasing control, restricting operating range of this concept to partial loads. ${ }^{7,8}$ The PPC concept focused on gasoline-like fuels (low cetane number) appears as a solution for the weaknesses observed under HCCI operation. The PPC uses direct fuel injection and injects during the compression-stroke, providing more moderate mixing times and more heterogeneous equivalence ratios distributions. Hence, low emissions can be still attained, but while retaining some control over the combustion timing with the injection event, ${ }^{9}$ although chemical kinetics still plays an important role. In this sense, the PPC strategy can present ignition problems with the use of higher-octane fuels (i.e., > 90 RON) at lower loads and higher EGR levels. ${ }^{10}$

Following this approach, more recent investigations have focused on the fuel reactivity control, which is commonly referred to as RCCI or dual-fuel CI. ${ }^{11,12}$ This concept, presents a dual fuel injection system. A port fuel injection (PFI) is used to inject the low reactivity fuel (low cetane number) at the intake manifold in order to create a homogeneous mixture, included EGR as well. Hence, the homogeneous mixture formed is compressed by the piston during the compression stroke. During this phase, the high reactivity fuel (high cetane number) is injected through the direct injector placed at the cylinder head and can be injected in more than one event. Once the mixture is compressed, the conditions at the combustion chamber will determine the autoignition of the mixture between low reactivity fuel, high reactivity fuel, fresh air and EGR rate. Therefore, by varying the relative amounts or injection timings of the two fuels, it is possible to create different fuel blends in order to adjust the combustion phasing. ${ }^{13}$ Achieving low NOx and PM emissions, due to the premixing time, and moreover, high thermal efficiency under different injection strategies. ${ }^{14,15}$ However, there are some challenges which limit the range of application such as excessive fuel consumption at low load and excessive pressure rise rate at high engine load. ${ }^{16}$

Taking into account the challenges which limit the range of application of the RCCI combustion and with the aim to operate with dual-fuel combustion over the whole engine map while the mechanical and emissions constraints are not exceeded, the authors proposed the dual-mode dual-fuel (DMDF) concept. ${ }^{17}$ The combustion strategy of the DMDF concept is modified as the engine load is increased. Hence, during the low load operation, the concept uses a fully premixed RCCI strategy. From medium load, the concept switches to highly premixed RCCI and dual-fuel diffusive strategy up to full load operation. ${ }^{17,18}$ The stability and control of combustion in each of the strategies depend mainly on the low reactivity/high reactivity fuel ratio, the injection settings and ER rate. In this sense, in RCCI operation, two diesel injections are used during the compression-stroke, where the last injection advances towards the top dead center (TDC) as the load increases. Already, in high load, for the dual-fuel diffusive strategy, it is shifted to a single diesel injection near the TDC, turning the combustion behavior more diffusive-like.

Thus, the objective of this experimental research is to evaluate the impact of different fuel injection strategies in each combustion process that encompasses the DMDF concept and its consequent impact on gaseous and particles emissions in a medium-duty diesel engine fueled with standard gasoline and diesel fuels. For this, a parametric study based on the independent modification of the diesel injection timing and the injection pressure was carried out in four operating points, which cover each of the combustion strategies (fully premixed RCCI, highly premixed RCCI and dual-fuel diffusion). 


\section{Material and methods}

\subsection{Test cell and engine description}

The experiments presented in this work are conducted in a single cylinder engine. By contrast, the engine is not a conventional single cylinder engine research engine, it is a hybrid solution between a multi cylinder engine and a single cylinder engine. The single cylinder engine used derives from a commercial medium-duty engine. The stock engine is a VOLVO D5K with 4 in-line cylinders developed for urban freight distribution purposes. Main specifications of the engine are shown in Table 1.

Table 1. Main characteristics of the base engine.

\begin{tabular}{ll}
\hline Characteristic & Value \\
\hline Style & 4 stroke, 4 cylinder DI diesel \\
Manufacturer/Model & Volvo/D5K240 \\
OEM EVO calibration & EURO VI \\
Maximum power & $177 \mathrm{~kW} @ 2200 \mathrm{rpm}$ \\
Maximum brake torque & $900 \mathrm{Nm@1200-1600} \mathrm{rpm}$ \\
Maximum in-cylinder pressure & $190 \mathrm{bar}$ \\
Maximum injection pressure & $2000 \mathrm{bar}$ \\
Bore x Stroke & $110 \mathrm{~mm}$ x 135mm \\
Connecting rod length & $212.5 \mathrm{~mm}$ \\
Crank length & $67.5 \mathrm{~mm}$ \\
Total displaced volume & $5100 \mathrm{~cm}^{3}$ \\
Compression ratio & $15.3: 1$ \\
\hline
\end{tabular}

Figure 1 presents the scheme of the test bench, including the engine and all the equipment required to carry out the test campaign. In order to apply the DMDF concept, the operation of one cylinder of the rest of the engine was isolated. In this way, one of the cylinders operates as an independent single-cylinder engine under dual-fuel strategies, while the three remaining cylinders are governed using the original engine control unit (ECU) to balance the cylinder-to-cylinder maximum pressure and load. From the figure, it is seen that the aftertreatment system has been removed, and the single-cylinder is not using the stock turbocharger system or the stock short route HP-EGR. Thus, a fresh air loop and a low-pressure exhaust gas recirculation (LP-EGR) loop has been coupled to provide the desired air management conditions at the single-cylinder. The intake required fresh air is provided by a screw compressor that provides compressed air from 1 to 3.7 bar. After the dryer, the exact air mass flow is measured by means of a volumetric flow meter. The exhaust line is equipped with a backpressure valve that generates the exhaust pressure desired by the engine operation point. This back-pressure valve contributes to the LP-EGR loop as well. Finally, the engine was connected to an AVL-APA 404 asynchronous dynamometer.

\section{[Insert Figure 1.]}

Regarding the injection system, a port fuel injection (PFI) was installed in the intake manifold to allow the fuel injection of the low reactivity fuel (gasoline). A common-rail injection system with a solenoid injector was used to inject the high reactivity fuel (diesel) directly into the cylinder. In addition, the original ECU was replaced by a Driven engine controller to allow full access to the injection control parameters of both DI and PFI systems. The main characteristics of the diesel and gasoline injectors are depicted in Table 2 . The fuel mass flow is measured by an AVL $733 S$ fuel balance.

Table 2. Diesel and gasoline fuel injector characteristics.

\begin{tabular}{llll}
\hline Diesel injector & & Gasoline injector & \\
\hline Actuation type & Solenoid & Injector style & Saturated \\
Steady flow rate @ $\mathbf{1 0 0}$ bar $\left[\mathbf{c m}^{3} / \mathbf{m i n}\right]$ & 1300 & Steady flow rate @ $\mathbf{3} \mathbf{~ b a r}\left[\mathbf{c m}^{3} / \mathbf{m i n}\right]$ & 980 \\
Number of holes & 7 & Included spray angle $\left[^{\circ} \mathbf{]}\right.$ & 30 \\
Hole diameter $[\boldsymbol{\mu m}]$ & 177 & Injector pressure $[\mathbf{b a r}]$ & 5.5 \\
Included spray angle $\left[^{\circ}\right]$ & 150 & Injection strategy & Single \\
\hline
\end{tabular}


The fuels used during the experiments were obtained directly from the regular petrol stations. Hence, the high reactivity fuel used was diesel (EN590) and the low reactivity fuel used was gasoline 95 research octane number (RON) (EN 228). Main physicochemical properties are presented in Table 3.

Table 3. Physical and chemical properties of the different fuels used.

\begin{tabular}{lll}
\hline Properties & Diesel & Gasoline \\
\hline Density $\left[\mathbf{k g} / \mathbf{m}^{\mathbf{3}}\right]\left(\mathbf{T}=\mathbf{1 5}^{\circ} \mathbf{C}\right)$ & 820 & 720 \\
Viscosity $\left[\mathbf{c m}^{2} / \mathbf{s}\right]\left(\mathbf{T}=\mathbf{4 0}^{\circ} \mathbf{C}\right)$ & 2.8 & - \\
RON [-] & - & 95.0 \\
MON[-] & - & 85.0 \\
Cetane number [-] & $>51$ & - \\
Lower heating value [MJ/kg] & 42.97 & 42.4 \\
\hline
\end{tabular}

The equipment used for the gaseous compounds measurement is the Horiba MEXA-ONE-D1-EGR analyzer. The five-gas Horiba analyzer accounts the molar fraction of $\mathrm{NO}, \mathrm{NO}_{2}, \mathrm{CO}$, unburned $\mathrm{HC}, \mathrm{CO}_{2}$ and $\mathrm{O}_{2}$. The sample acquired by the equipment flows towards the analyzer through a heated line $\left(\approx 190^{\circ} \mathrm{C}\right)$ in order to avoid condensation of the HC species. Every specie of the exhaust gases is analyzed by a specific device.

Particle size distribution (PSD) was measured using a single-stage dilution system connected to a scanning mobility particle sizer (SMPS). An MD19-3E Rotating Disk was employed as a dilution system to dilute the sample for particle measurement. This dilution system uses a unique rotating disk method and two disks with eight and ten cavities each, which are used to select a dilution ration in the range of 15:1 to 3000:1. The rotating disk cavities capture a portion of the raw exhaust and this portion is mixed with preheated and filtered dilution air.

The MD19-3E RD dilution system allows heating the dilution unit and the dilution air to temperatures of $200{ }^{\circ} \mathrm{C}$. This heating method keeps liquids evaporated above their dew point and avoids generation of volatile nanoparticles by nucleation. This thermal conditioning of the sample allows for the reduction of the concentration range within the acceptable limits of the particle measuring device and provides accurate information on the concentration of particles generated during the combustion process. ${ }^{19}$

The PSD is measured using a TSI Scanning Particle Sizer (SMPS 3936L75). This system contains an inertial impactor which is used to remove particles larger than $1 \mu \mathrm{m}$. Additionally, the system is equipped with a Long Differential Mobility Analyzer (LDMA 3081) that allows to select the particle size to be measured, with a range from 2.5 to $1000 \mathrm{~nm}$ and finally, the system has a Condensation Particle Counter (CPC 3775) to count particles with sizes down to $4 \mathrm{~nm}$. In order to dilute the exhaust sample, to measure PSD and to obtain reliable values, in this work was used the measurement methodology presented by Desantes et al. ${ }^{20}$ The accuracy of the instrumentation used in the test cell is summarized in Table 4.

Table 4. Accuracy of the instrumentation used in the test cell.

\begin{tabular}{llll}
\hline Device & Manufacturer and model & Variable measured & Accuracy \\
\hline Air flow meter & Elster RVG G100 & Fresh air mass flow & $\pm 0.1 \%$ \\
Fuel balance & AVL 733S & Gasoline/diesel fuel mass flow & $\pm 0.2 \%$ \\
Gas analyzer & Horiba MEXA-ONE-D1-EGR & NOx, CO, HC, CO, $\mathrm{O}_{2}$ & $4 \%$ \\
SMPS & TSI SMPS-3936L75 & Particles number and size & $3.5 \%$ \\
Piezoelectric transducer & Kistler 6125C & In-cylinder pressure & $\pm 1.25 \mathrm{bar}$ \\
Piezoelectric transducer & Kistler 4045A10 & Intake/exhaust pressure & $\pm 25 \mathrm{mbar}$ \\
Thermocouple & TC direct type K & Intake/exhaust tmperature & $\pm 2.5^{\circ} \mathrm{C}$ \\
\hline
\end{tabular}

\subsection{Theoretical tools and calculations method}

To achieve the desired load in the DMDF operation, an adequate adjustment of the injection parameters, LP-EGR rate and gasoline fraction (GF) is necessary. In this sense, the GF (equation (1)) is defined as the mass ratio of gasoline versus the total fuel injected.

$$
G F[\%]=\frac{m_{\text {gasoline }}}{m_{\text {gasoline }}+m_{\text {diesel }}} \cdot 100
$$

The EGR rate is obtained taking in account the $\mathrm{CO}_{2}$ at the intake and at the exhaust and the atmospheric content of $\mathrm{CO}_{2}$. Hence, the EGR rate is calculated according to equation (2), where $\mathrm{CO}_{2}$ atmospheric is equal to 400 ppm. $\mathrm{CO}_{2}$ concentration at the intake air at the exhaust are introduced in ppm. 


$$
E G R[\%]=\frac{\mathrm{CO}_{\text {2intake }}-\mathrm{CO}_{\text {2atmospheric }}}{\mathrm{CO}_{\text {2exhaust }}-\mathrm{CO}_{2 \text { atmospheric }}} \cdot 100
$$

The combustion analysis was carried out with an in-house 0-D thermodynamic model called CALMEC. The theoretical principles of this 0-D model are based on applying the first law of thermodynamics to solve open systems considering the fuel injection and blow-by flow. This diagnostic model uses the in-cylinder pressure signal and the mean variables recorded during the experiments (engine speed, coolant, oil, intake and exhaust temperatures, air, EGR and fuel mass flow) as its main inputs, to obtain a wide variety of combustion parameters, such as the rate of heat release (RoHR), main combustion phases (CA10, CA50 and CA90: crank angle after TDC (CA aTDC) in which the $10 \%, 50 \%$, and $90 \%$ of the total heat release has been released during the combustion process, respectively), peak cylinder pressure $\left(\mathrm{P}_{\max }\right)$, maximum pressure gradient $\left(\mathrm{dP} / \mathrm{d} \alpha_{\max }\right)$ and indicated mean effective pressure (IMEP). The full description of the model can be found in Payri et al. ${ }^{21}$

In addition, the combustion duration (CA90-CA10) was determined, which is defined as the time elapsed from the SoC (represented by the CA10) up to the end of the combustion (represented by the CA90). The diesel mixing time (Mix. Time), which is the interval between the end of fuel injection (EoI) of the last diesel injection and the SoC, was also calculated. It is important to consider that an increase in Mix. Time positive values, results in leaner equivalence ratios at SOC. However, negative values indicate the coexistence of fuel injection and the combustion process during a certain period, which will be higher while the Mix. Time are lower (or greater in absolute value).

The particle size distribution (PSD) allows an analysis of the complex mix of volatile, non-volatile species and soot agglomerates that represent the particles concentration emitted by ICEs. The PSD can show a bimodal structure with a nucleation-mode representing particles with a size smaller than $30 \mathrm{~nm}$ or for some authors than $50 \mathrm{~nm}$, and accumulation-mode with particles larger than these sizes. ${ }^{22,23}$ The nucleation-mode particles are mostly volatile or semi-volatile condensate that can nucleate to form particles with a larger size. Its formation process occurs mainly due to low combustion temperatures or during dilution and cooling of the exhaust flow. ${ }^{24}$ The accumulation-mode is formed by agglomerates carbonaceous compounds in which volatile condensates can adhere to their surfaces. The high combustion temperature and rich equivalence ratio zones are the two main factors that favor the formation process of soot particles and can occur both in premixed and non-premixed combustion. ${ }^{25,26}$ The formation of the first precursors and their evolution to the final solid particles is mainly based on the following steps: pyrolysis, nucleation, surface growth, agglomeration and oxidation, in the works of Reijnders et al..$^{27}$ and Überall et al. ${ }^{28}$ this evolution process is described in detail.

The PSD can be described as the combination of two individual distributions (nucleation-mode and accumulation-mode) assuming the log-normal size distribution, according to equation (3). ${ }^{29}$ Where $x$ is the ratio of the total concentrations number of two distributions, $\mathrm{d}_{\mathrm{p} 1}, \mathrm{~d}_{\mathrm{p} 2}, \mathrm{~d}_{\mathrm{pg} 1}, \mathrm{~d}_{\mathrm{pg} 2}, \sigma_{1}$ and $\sigma_{2}$ are the geometric mean diameters, median diameters, and geometric standard deviations of each peak, and $\mathrm{N}_{\mathrm{i}}$ is the $\mathrm{PN}$ of particle size $\mathrm{d}_{\mathrm{pi}}$.

$$
\frac{d N_{i}}{d \log d p_{i}}=\frac{1-x}{\sqrt{2 \pi} \log \sigma_{g 1}} \cdot e^{-\frac{\log ^{2}\left(\frac{d p_{1}}{d p_{11}}\right)}{2 \log ^{2} \sigma_{g 1}}}+\frac{1-x}{\sqrt{2 \pi} \log \sigma_{g 2}} \cdot e^{-\frac{\log ^{2}\left(\frac{d p_{2}}{d p_{2}}\right)}{2 \log ^{2} \sigma_{g 2}}}
$$

To calculate the total particle number concentration $(\mathrm{dN})$, the equations (4) was used for each distribution mode:

$$
d N=\sum_{d p(\text { low })}^{d p(u)} d N_{i}
$$

\section{$2.4 \quad$ Test schedule}

In order to assess the three different combustion strategies (fully premixed RCCI, highly premixed RCCI and dual-fuel diffusion) required to complete the operation over the whole engine map, during the DMDF concept, four operating points were selected, as shown in Figure 2. These combustion strategies are highly dependent on the engine speed and load. The GF was set to the highest value that could be achieved with the highest combustion stability. As illustrated in Figure 2, this resulted in a minimum GF of $40 \%$ at low load to avoid excessive HC emissions and combustion instabilities, increasing to nearly $80-90 \%$ in the engine map region between 5 and 10 bar IMEP for all engine speeds. At high load, it was necessary to decrease the GF to avoid excessive maximum pressure rise rate. For the fully premixed RCCI strategy the chosen operating point was at $25 \%$ load and $950 \mathrm{rpm}$ and it was denoted as A950, for the highly premixed RCCI strategy the operating point is the B1500 at 50\% load and $1500 \mathrm{rpm}$, and finally for the dual-fuel diffusion strategy, two operating points, C2000 and D2200, the first at 75\% load and $2000 \mathrm{rpm}$ and the second at $100 \%$ load and $2200 \mathrm{rpm}$. 


\section{[Insert Figure 2.]}

Once the operating points were defined, a parametric study was carried out based on the independent modification of two diesel injection parameters: the injection pressure (IP) and the start of injection (SoI) of the main injection. from a baseline case, which corresponds to the nominal engine configuration in each steadystate operating point. The main characteristics of these operating points are shown in Table 5, where the baseline engine settings are indicated in bold.

The start of gasoline injection timing was fixed 10 CA after the intake valve opening (-340 CA aTDC) to avoid the fuel pooling on the intake valve seats. A single diesel injection was used in the C2000 and B2200 operating points and a double diesel injection strategy in the A950 and B1500 operating points. The pilot injection timing was not analyzed due to its reduced impact on the pollutant emissions. In order to study the influence of one parameter, it was varied while the other parameters were set to the baseline values. The air mass flow ( $\left.\mathrm{m}_{\text {air }}\right), \mathrm{m}_{\text {fuel }}$ and EGR rate were kept constant in all tests for each operation point, as shown in Table 5. This procedure is very important to avoid the influence of these parameters on the in-cylinder conditions and consequently on combustion process and exhaust emissions, leaving only the IP and SOImain variation as responsible for changes in emissions values.

Table 5. Experimental plan for the parametric study.

\begin{tabular}{|c|c|c|c|c|c|c|c|c|c|c|}
\hline Operating Point & $\begin{array}{c}\text { Speed } \\
{[\mathrm{rpm}]}\end{array}$ & $\begin{array}{l}\text { IMEP } \\
{[\mathrm{bar}]}\end{array}$ & $\begin{array}{l}\text { SOIPFI } \\
\text { [CA aTDC] }\end{array}$ & $\begin{array}{l}\text { SOI }_{\text {pilot }} \\
\text { [CA aTDC] }\end{array}$ & $\begin{array}{l}\text { SOI }_{\text {main }} \\
{[\mathrm{CA} \text { aTDC] }}\end{array}$ & $\begin{array}{l}\text { IP } \\
\text { [bar] }\end{array}$ & $\begin{array}{l}\text { GF } \\
{[\%]}\end{array}$ & $\begin{array}{l}\text { mfuel } \\
{[\mathrm{g} / \mathrm{s}]}\end{array}$ & $\begin{array}{l}\text { mair } \\
{[\mathrm{g} / \mathrm{s}]}\end{array}$ & $\begin{array}{l}\text { EGR } \\
{[\%]}\end{array}$ \\
\hline \multirow{3}{*}{$\begin{array}{l}\text { A950 } \\
\text { Fully premixed } \\
\text { RCCI }\end{array}$} & 950 & 5.7 & -340 & -43 & -23 & 1000 & 80 & 0.27 & 13.45 & 20 \\
\hline & & & & & -28 & 1200 & & & & \\
\hline & & & & & -33 & 1400 & & & & \\
\hline \multirow{3}{*}{$\begin{array}{l}\text { B1500 } \\
\text { Highly premixed } \\
\text { RCCI }\end{array}$} & 1500 & 12.5 & -340 & -40 & -3 & 1000 & 70 & 0.87 & 20.06 & 50 \\
\hline & & & & & -5 & 1200 & & & & \\
\hline & & & & & -7 & 1400 & & & & \\
\hline C2000 & 2000 & 18.0 & -340 & - & -3 & 1000 & 50 & 1.75 & 39.47 & 43 \\
\hline \multirow[t]{2}{*}{ Dual-fuel diffusion } & & & & & -6 & 1200 & & & & \\
\hline & & & & & -9 & 1400 & & & & \\
\hline D2200 & 2200 & 20.8 & -340 & - & -8 & 1000 & 30 & 2.42 & 52.57 & 30 \\
\hline \multirow[t]{2}{*}{ Dual-fuel diffusion } & & & & & -11 & 1200 & & & & \\
\hline & & & & & -14 & 1400 & & & & \\
\hline
\end{tabular}

Finally, in order to be able to detect possible errors during the engine tests, the methodology defined by Benajes et al. ${ }^{30}$, has been applied in the present investigation.

\section{Results and discussion}

The influence of different injection strategies on combustion process and pollutant emissions will be analyzed in this section.

\subsection{Influence of diesel main injection timing (SOI main)}

Before beginning to study the impact of diesel main injection timing on the combustion process and pollutant emissions, it is very important to carry out an analysis of the different combustion processes involved in this investigation. Figure 3 shows the combustion development through the RoHR profile and the in-cylinder pressure (Pcyl) for each SOI main at each operating point. The adjustment of these injection parameters and the GF are used to reach the desired engine load. ${ }^{17}$

\section{[Insert Figure 3.]}

The combustion strategy at the A950 operating point is considered as fully premixed RCCI (Figure 3 (a)), which is characterized by a short duration RoHR profile in Gaussian-shape. This strategy is used at low engine load and is achieved by a double diesel injection with very advanced injection timings, which provide enough time for the mixture preparation before the SoC. Because of the high mixing time available low NOx and solid particles emissions are obtained. As a counterpart, the diesel injection timing has not much influence on the combustion phasing, which is basically governed by the fuel reactivity through the gasoline fraction, this being 
a limitation at high loads. This occurs because as engine load increases, excessive in-cylinder pressure rates appear, favoring thermodynamic conditions for a charge composed of homogeneously mixed gasoline and highly premixed diesel, promotes the onset of knocking-like combustion. As the engine load is increased, the combustion strategy can be defined as highly premixed RCCI (B1500 operating point, Figure 3 (b)). This combustion strategy is also achieved using a double diesel injection pulse, but in this case, the second injection is shift towards the top dead center (TDC). Therefore, the mixing time of the injected diesel fuel is reduced in the second diesel injection, varying between 0 and negative values, while the diesel pilot injection improves reactivity in the crevices zone, where high amount of gasoline gets trapped. ${ }^{31}$ This strategy provides more combustion control due to the partial diffusion burning, since the combustion phase is very sensitive to the second diesel injection timing. This allows to avoid excessive pressure gradients and the NOx emissions are still low, but particle emissions start to be penalized due to the lower mixing time for the second diesel injection. However, from $75 \%$ up to full load, it is necessary to modify the injection strategy, as the increase in-cylinder pressure rates do not allow an increase in the mixture reactivity before the ignition through a diesel pilot injection, due to the high chance of an onset of knocking combustion. This combustion strategy can be defined as dual-fuel diffusive, only a single diesel injection is used that determines the SoC, as shown at C2000 and D2200 operating points in Figure 3 (c)-(d). Even so, the combustion typically starts with a high RoHR peak due to the gasoline burning during the first diesel reactions. After this, the combustion event is characterized by a long diesel-like tail during the expansion stroke. Because of the diffusive nature of the combustion, high levels of PM emissions are obtained, and NOx emissions cannot be kept low.

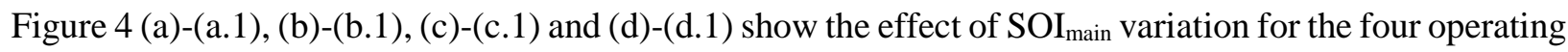
points on the main combustion parameters: SoC (represented by CA10), combustion phase (represented by the CA50), $\mathrm{dP} / \mathrm{d} \alpha_{\max }$ and $\mathrm{P}_{\max }$. In general, it is possible to observe how the combustion phase is into the expansionstroke for the different SOIs and operating points. Therefore, as expected from the trends already observed in RoHR profile and Pcyl (Figure 3), the delay of CA10 and CA50 leads to the combustion process in conditions where the temperature and pressure are lower due to the cylinder volume expansion. This behavior slows chemical reactions and, consequently, decreases the $\mathrm{dP} / \mathrm{d} \alpha_{\max }, \mathrm{P}_{\max }$ and combustion temperature values.

\section{[Insert Figure 4.]}

At A950 operating point, the SOI main delay did not significantly affect the fully RCCI combustion. The results showed only a slight advance of CA10 and CA50 for the most delayed SOI main and consequently an increase in $P_{\max }, \mathrm{dP} / \mathrm{d} \alpha_{\max }$. A significant delay in this injection timing gives less time for the diesel to mix with both air and gasoline, resulting in a richer and more reactive local mixture when approaching TDC, thereby shortening the ignition delay. Behavior that is reflected in Figure 4 (a.2), with a significant reduction in the Mix. Time of this most delayed injection timing. At B1500 operating point, a higher degree of control over combustion was observed in the highly premixed RCCI strategy. As can be seen in Figure 4 (b)-(b.1), the delay of $\mathrm{SOI}_{\text {main }}$ retards the combustion phase and decreases the $\mathrm{P}_{\text {max }}$. This trend is due to the partial diffusion burning in the combustion process, as shown in Figure 4 (b.2) with negative Mix. Time values. As the SOI main is delayed the Mix. Time values decrease, indicating an increase in the period of coexistence of the diesel injection and the combustion process. Additionally, at B2000 and C2200 operating points, combustion processes were diffusionlike. Figure 4 (c.2)-(d.2) illustrate how the 2nd injection timing delay tends to lead to increasingly negative Mix Time values. In these conditions, the $\mathrm{SOI}_{\text {main }}$ delay increases the combustion duration, as it can be observed with the increase in CA90-CA10 and, consequently increases the time of the diffusion burning of the diesel fuel.

With regard to the gaseous compound emissions in A950 operating point (fully premixed RCCI strategy, Figure 5 (a)-(a.2)) no significant variations were obtained in the emissions of these pollutants with the SOI main variation. Only a slight decrease in $\mathrm{CO}$ emissions and a small increase in NOx emissions were observed with the $\mathrm{SOI}_{\text {main }}$ delay. In both cases, this behavior is related to the increase in $\mathrm{P}_{\max }, \mathrm{dP} / \mathrm{d} \alpha_{\max }$ values and, consequently, to the combustion temperature that provides the delay of this event, as shown in Figure 4 (a.1). Taking into account that the $\mathrm{CO}$ increases, when the conversion process of $\mathrm{CO}$ to $\mathrm{CO}_{2}$ is limited, it is mainly due to two factors: lower combustion temperatures, that decrease the conversion reactions and the lack of oxygen in the reaction zone. ${ }^{32}$ Conversely, NOx formation occurs from the reaction between nitrogen and oxygen during the combustion process at high temperatures and increases exponentially with the increase in combustion temperature. ${ }^{33}$ There was also a slight increase in HC emissions with the advance of SOI $\mathrm{I}_{\text {main, }}$ as shown in Figure 5 (a). This trend could be related to an increase in fuel located in quench areas, such as the crevices. ${ }^{34}$ This is because a significant advance of this injection facilitating that part of the fuel injected is not directed into the bowl, being located in the squish and crevice regions. 


\section{[Insert Figure 5.]}

Unlike the fully premixed RCCI condition, in highly premixed RCCI strategy the diesel main injection timing is considerably delayed towards the TDC. Under these conditions, the SOI main $_{\text {delay provides an }}$ increasingly delayed combustion phase during the expansion stroke, and a decrease in $P_{\max }$ and $\mathrm{dP} / \mathrm{d} \alpha_{\max }$, as shown at B1500 operating point (Figure 4 (b)-(b-1)). This behavior justifies the decrease in NOx emissions and the increase in $\mathrm{CO}$ emissions, as illustrated in Figure 5 (b.1)-(b.2). In addition, HC emissions remained relatively constant, which shows that the $\mathrm{SOI}_{\text {main }}$ delay is key to reducing $\mathrm{HC}$ emissions. A similar trend was observed at C2000 and D2200 operating points in diffusive dual-fuel condition, although with the variations of CO and NOx emissions are more marked, as shown in Figure 5 (c.1)-(c.2) and (d.1)-(d.2). In diffusive dual-fuel strategy, the SOI $I_{\text {main }}$ determines the start and the combustion phase, therefore the delay of $\mathrm{SOI}_{\text {main }}$ slows the combustion process and decreases the $\mathrm{P}_{\max }$ and $\mathrm{dP} / \mathrm{d} \alpha_{\max }$ (Figure 4 (c.1)-(d.1)), impacting on CO and NOx emissions.

Regarding PM emissions, at A950 operating point (fully premixed RCCI strategy, Figure 6 (a)-(a.1)), it is shown that despite not having significant variations in total particle concentrations, it was observed that the nucleation-mode particles increased slightly, while the accumulation-mode particles decreased. The SOI main advance increases the mixing time (Figure 4 (a.2)) and this reduces the local fuel equivalence ratios and incylinder charge reactivity, decreasing the combustion temperature ( $P_{\max }$ values in Figure 4 (a.1)), which implies that, on the one hand, the volatile condensation process is favored and consequently the nucleation-mode particles increase and, on the other hand, the primary soot particle formation is limited, decreasing the concentration of accumulation-mode particles..$^{35,36}$

\section{[Insert Figure 6.]}

In highly premixed RCCI condition, part of the diesel fuel injected in the second injection is burned through a diffusive flame, i.e., the SoC occurs before the fuel injection is finished. This behavior can be quantified in B1500 operating point, with the negatives Mix. Time values in Figure 4 (b.2). As can be observed as the SOI main is delayed, the Mix. Time decreases, which makes the combustion behavior more diffusive-like, favoring the nuclei-precursor particles formation process. ${ }^{37,38}$ With more available nuclei particles, the surface growth and coagulation processes are intensified, increasing the sizes and total particles concentration, ${ }^{24,39}$ as shown in Figure 6 (b.1). In addition, at the A950 and B1500 operating points, the size distribution shifted to larger sizes, increasing the size and concentration of accumulation-mode particles and decreasing the nucleation-mode particles, as shown in Figure 6 (a)-(a.1) and (b)-(b.1). This result should be a consequence of the increase in carbonaceous particles that are generated in these conditions, which provides a greater amount of solid surface for the absorption of volatile condensates to be greater. ${ }^{27}$

At the C2000 and D2200 operating points, the combustion is characterized as being almost entirely diffusive. During this combustion process, the particles are formed in the diffusion flame just after the lift-off rich premixed burn region. ${ }^{40}$ The size and concentration of particles increase when travelling inside the diffusion flame; and finally, the soot particles are partially oxidized in the diffusion flame front. ${ }^{41}$ Therefore, particle emissions are the result of a complex balance between in-cylinder particles formation and oxidation.

Taking this information into account, it is possible to understand why the $\mathrm{SOI}_{\text {main }}$ advance considerably increases the particle emissions in dual-fuel diffusion strategy, as illustrated in Figure 6 (c)-(c.1) and (d)-(d.1). On the one hand, in both operating points, the advance of this event prolongs the time in which the fuel is burned by diffusion in the combustion process, as can be seen with the increase in CA90-CA10 and the decrease in Mix. Time. (Figure 4 (c.2) (d.2)), favoring to a large extent the process of particle formation . On the other hand, combustion is delayed in the expansion-stroke where the combustion temperatures are lower (Figure 4 (c.1) and (d.1), with $\mathrm{dP} / \mathrm{d} \alpha_{\max }$ values) making the particle oxidation process difficult. This result is in-line with that obtained by Desantes et al. ${ }^{42}$

\subsection{Influence of injection pressure (IP)}

The effect of the parametric variation of IP on combustion process for the four operating points can be observed in the RoHR profiles and cylinder pressure in Figure 7 and in the main parameter values of the combustion process in Figure 8.

At A950 operating point, the IP variation did not have a significant impact on the combustion process, as proven by the relatively constant values of the combustion parameters in Figure 7 (a) and Figure 8 (a)-(a.2). However, although the impact was less than that provided by the SOI main variation, at the B1500, C2000 and D2200 operating points, if there are variations in the combustion process, this behavior is due to the diffusive character of the combustion strategies carried out at these operating points. This is taking into account, that the 
amount of fuel injected is the same for the different IPs in each operating point. When the injection pressure is lowered, the injection time will be longer and, the combustion duration increases, so further delaying the combustion relative to TDC and implying lower instantaneous temperature and pressure profiles. These results can be verified with the increase in CA90-CA10 and the decrease in Mix. Time, as well as the decrease in $\mathrm{P}_{\max }$ and $\mathrm{dP} / \mathrm{d} \alpha_{\max }$, in Figure 8 (b)-(b.2), (c)-(c.2) and (d)-(d.2).

\section{[Insert Figure 7.]}

\section{[Insert Figure 8.]}

Figure 9 shows the gaseous emissions, as can be noted and as expected from the reduced variation in the combustion process, at A950 operating point no significant alterations occurred in the gaseous compounds for the different IPs. However, at B1500, C2000 and D2200 operating points, where the highly premixed RCCI and dual-fuel diffusion strategies are used, there was a slight increase in CO emissions and a decrease in NOx emissions with the decrease in IP, in both cases, this trend is related to the reduction of the combustion temperature that limits the CO oxidation and the NOx formation. The decrease in $\mathrm{dP} / \mathrm{d} \alpha_{\max }$ and $\mathrm{P}_{\max }$ in Figure 8 (b.1), (c.1) and (d.1) can justify this decrease in the combustion temperature.

\section{[Insert Figure 9.]}

Regarding PM emissions, under fully premixed RCCI conditions at A950 operating point, there were no significant alterations in particle emissions with the IP variation, as shown in Figure 10 (a)-(a.1). The significant advance of the start of the injection reduces the impact of injection pressure modifications on the mixing time and the particle formation process. At B1500 operating point, the decrease in IP increases the diesel burning by diffusion, as illustrated in Figure 8 (b.2) with the increasingly negative Mix. Time values, facilitates the soot primary particle formation and also reduces the particle oxidation process by delaying the combustion process in the expansion-stroke (Figure 8 (b)-(b.2)), where the combustion temperatures are lower. This behavior that is confirmed with the rise in accumulation-mode particles, in Figure 10 (b.1). The same trend was observed but in a larger scale in the C2000 and D2200 in dual-fuel diffusion conditions when the IP decreases, as shown in Figure 10 (c) and (d), confirming that the combustion process delay (Figure 8 (c) and (d)) and the increase of its diffusive character (Figure 8 (c.2) and (d.2)) are two parameters that increase the solid particles emissions. Furthermore, higher IP values also provide a flame lift-off growth, i.e., the distance from the injector nozzle to the starting combustion zone rises. This, in turn, increases the amount of air entrained into the spray before the fuel reaches flame zones and, the fuel is better mixed with the surrounding air. ${ }^{24,43}$ As a result, higher mixing speeds and higher heat release rates are achieved, which reduces the particle formation and facilitates their oxidation process, respectively.

\section{[Insert Figure 10.]}

The previous experimental results also allow an analysis of the gaseous and particle emissions between the different combustion strategies in DMDF concept. In the fully premixed RCCI strategy, the particle size distribution was dominated by nucleation-mode, as shown in Figure 10 (a). Coincidentally, in these conditions, the highest HC emissions were also observed (Figure 9 (a)), confirming the hypothesis, that the formation of nucleation-mode particles is mainly due to the nucleation, condensation and coagulation of the unburned hydrocarbons, which are produced due to a comparatively lower combustion temperature in premixed combustion. ${ }^{24,44}$ In this case, the increase in emissions of HC and CO is associated with the high level of GF $(80 \%)$ and the lower in-cylinder fuel mixture reactivity, which makes more difficult to burn the greater amount of premixed gasoline located in the crevices and squish region. By contrast, the lower combustion temperatures greatly limited the NOx formation, as illustrated in Figure 9 (a.2).

The need to increase the load on the engine requires the use of the highly premixed RCCI strategy. In this condition, the mixture reactivity increases through the decrease of GF to $70 \%$ and the $\mathrm{SOI}_{\text {main }}$ delay. Therefore, the higher temperatures reached during combustion reduce $\mathrm{HC}$ and $\mathrm{CO}$ emissions and increase NOx emissions compared to the fully premixed RCCI strategy, although in relation to this last gaseous pollutant, its values did not reach very high levels, which can be seen in Figure 9 (b)-(b.2). The particle size distribution shows a bimodal structure (Figure $10(\mathrm{a})$ ), with a reduced concentration of nucleation-mode particles and a high concentration of accumulation-mode particles. Although there is a percentage of diesel fuel premixed due to the significant 
advance of the first diesel injection, the diffusion burning of the fuel injected in the second injection greatly facilitates the process of soot particles formation and consequently highest accumulation-mode particles. Finally, in dual-fuel diffusion condition, the GF is reduced significantly, and the premix of the diesel fuel is eliminated suppressing the diesel pilot injection. This promotes a diffusive combustion process similar to the $\mathrm{CDC}$, where high in-cylinder temperatures are reached, reducing the $\mathrm{HC}$ and $\mathrm{CO}$ emissions but increasing the NOx and PM emissions, in comparison with the fully premixed RCCI and highly premixed RCCI strategies. This behavior that becomes more evident as the engine load increases, as shown in Figure 9 (c)-(c.2), (d)-(d.2) and Figure 10 (c)-(c.1) and (d)-(d.1).

\section{Conclusions}

In this research, the effects of diesel main injection timing (SOI $\mathrm{Sain}_{\text {) }}$ and injection pressure (IP) on the combustion process and its consequent impact on gaseous emissions and the particle size distribution from the DMDF concept in a CI engine were investigated experimentally. For this, a parametric study was conducted based on the independent modification of each parameter under study in four steady-state operating points that encompass the combustion strategies (fully premixed RCCI, highly premixed RCCI and dual-fuel diffusion) necessary to cover the entire map without affecting engine thermal efficiency. The results showed that a finer adjustment of the injection parameters can achieve a better balance between the different pollutant emissions and, in some cases, significantly reduce the particle emissions.

In fully premixed RCCI conditions, the $\mathrm{SOI}_{\text {main }}$ advance increases the time available for the mixture preparation before the start of the combustion, decreasing the fuel-rich zones and combustion temperatures, which represents a simultaneous reduction in the concentration of accumulation-mode particles and NOx emissions. During the highly premixed RCCI strategy, the SOI main delay and the rise of IP increase the mixture reactivity, advancing the combustion phase. This facilitates the particle oxidation process and CO conversion, significantly reducing both pollutants. Although under these conditions, the HC emissions remained relatively constant if there was a slight increase in NOx emissions. Finally, due to the diffusive nature of the combustion in dual-fuel diffusion strategy, the $\mathrm{SOI}_{\text {main }}$ advance and the increase in IP provide the development of a combustion process that is increasingly closer to the TDC, where higher combustion temperatures are reached, favoring to a large extent the oxidation process of particles, but increasing NOx emissions. Even though, under these conditions a reduction in $\mathrm{CO}$ emissions was also observed, it is necessary to set intermediate values of the injection parameters in order to reduce the NOx formation process.

In comparative terms between the different combustion strategies, the following results were obtained. In the fully RCCI strategy, high concentrations of nucleation-mode particles and HC emissions were observed, confirming the close relationship between both pollutants. However, the concentrations of accumulation-mode particle and NOx emissions were much lower than during the highly premixed RCCI strategy. In this last combustion strategy, the higher in-cylinder temperatures favored the solid particles formation, increasing the concentration of accumulation-mode and NOx emissions, but the HC and CO emissions had a significant decrease. A similar trend in the emissions of these pollutants but on a larger scale was obtained in dual-fuel diffusion, due to the diesel premix elimination and the increase in the diffusion combustion process.

\section{Acknowledgments}

This investigation has been funded by VOLVO Group Trucks Technology. The authors also acknowledge the Spanish economy and competitiveness ministry for partially supporting this research (HiReCo TRA201458870-R).

\section{Declaration of conflicting interests}

The authors declare that there is no conflict of interest.

\section{References}

1. Oppenauer KS, Alberer D. Soot formation and oxidation mechanisms during diesel combustion: Analysis and modeling impacts. Int J Engine Res 2014; 15: 954-964.

2. Rezaei R, Dinkelacker F, Tilch B, et al. Phenomenological modeling of combustion and NO ${ }_{x}$ emissions using detailed tabulated chemistry methods in diesel engines. Int J Engine Res 2016; 17: 846-856.

3. Sarangi AK, Garner CP, McTaggart-Cowan GP, et al. The effects of split injections on high exhaust gas recirculation low-temperature diesel engine combustion. Int J Engine Res 2013; 14: 68-79.

4. Shi L, Xiao W, Li M, et al. Research on the effects of injection strategy on LTC combustion based on two-stage fuel injection. Energy 2017; 121: 21-31. 
5. Singh AP, Agarwal AK. Combustion characteristics of diesel HCCI engine: An experimental investigation using external mixture formation technique. Appl Energy 2012; 99: 116-125.

6. Sofianopoulos A, Rahimi Boldaji M, Lawler B, et al. Investigation of thermal stratification in premixed homogeneous charge compression ignition engines: A Large Eddy Simulation study. Int J Engine Res. Epub ahead of print 2018. DOI: 10.1177/1468087418795525.

7. Lu X, Han D, Huang Z. Fuel design and management for the control of advanced compression-ignition combustion modes. Prog Energy Combust Sci 2011; 37: 741-783.

8. Ryan TW, Matheaus AC. Fuel Requirements for HCCI Engine Operation. In: SAE Technical Paper, 2003-011813. DOI: $10.4271 / 2003-01-1813$.

9. Benajes J, Novella R, De Lima D, et al. Impact of injection settings operating with the gasoline Partially Premixed Combustion concept in a 2-stroke HSDI compression ignition engine. Appl Energy 2017; 193: 515530.

10. Benajes J, García A, Domenech V, et al. An investigation of partially premixed compression ignition combustion using gasoline and spark assistance. Appl Therm Eng 2013; 52: 468-477.

11. Benajes J, García A, Monsalve-Serrano J, et al. Evaluating the reactivity controlled compression ignition operating range limits in a high-compression ratio medium-duty diesel engine fueled with biodiesel and ethanol. Int J Engine Res 2017; 18: 66-80.

12. Yazdani K, Amani E, Naderan H. Multi-objective optimizations of the boot injection strategy for reactivity controlled compression ignition engines. Int J Engine Res. Epub ahead of print 31 August 2018. DOI: 10.1177/1468087418795599.

13. Benajes J, Molina S, García A, et al. Effects of direct injection timing and blending ratio on RCCI combustion with different low reactivity fuels. Energy Convers Manag 2015; 99: 193-209.

14. Kavuri C, Kokjohn SL, Klos DT, et al. Blending the benefits of reactivity controlled compression ignition and gasoline compression ignition combustion using an adaptive fuel injection system. Int J Engine Res 2016; 17: 811-824.

15. Ebrahimi M, Najafi M, Jazayeri SA. Multi-input-multi-output optimization of reactivity-controlled compressionignition combustion in a heavy-duty diesel engine running on natural gas/diesel fuel. Int J Engine Res. Epub ahead of print 26 February 2019. DOI: 10.1177/1468087419832085.

16. Benajes J, Pastor J V., García A, et al. A RCCI operational limits assessment in a medium duty compression ignition engine using an adapted compression ratio. Energy Convers Manag 2016; 126: 497-508.

17. Benajes J, García A, Monsalve-Serrano J, et al. Achieving clean and efficient engine operation up to full load by combining optimized RCCI and dual-fuel diesel-gasoline combustion strategies. Energy Convers Manag 2017; 136: $142-151$.

18. Benajes J, García A, Monsalve-Serrano J, et al. Gaseous emissions and particle size distribution of dual-mode dual-fuel diesel-gasoline concept from low to full load. Appl Therm Eng 2017; 120: 138-149.

19. Kasper M. The Number Concentration of Non-Volatile Particles - Design Study for an Instrument According to the PMP Recommendations. In: SAE Technical Paper. 2004-01-0960. DOI: 10.4271/2004-01-0960.

20. Desantes JM, Bermúdez V, Pastor J V, et al. Methodology for measuring exhaust aerosol size distributions from heavy duty diesel engines by means of a scanning mobility particle sizer. Meas Sci Technol 2004; 15: 20832098.

21. Payri F, Olmeda P, Martín J, et al. A complete 0D thermodynamic predictive model for direct injection diesel engines. Appl Energy 2011; 88: 4632-4641.

22. Lapuerta M, Armas O, Gómez A. Diesel Particle Size Distribution Estimation from Digital Image Analysis. Aerosol Sci Technol 2003; 37: 369-381.

23. Yinhui W, Rong Z, Yanhong Q, et al. The impact of fuel compositions on the particulate emissions of direct injection gasoline engine. Fuel 2016; 166: 543-552.

24. Saxena MR, Maurya RK. Effect of premixing ratio, injection timing and compression ratio on nano particle emissions from dual fuel non-road compression ignition engine fueled with gasoline/methanol (port injection) and diesel (direct injection). Fuel 2017; 203: 894-914.

25. Agarwal AK, Gupta T, Kothari A. Particulate emissions from biodiesel vs diesel fuelled compression ignition engine. Renew Sustain Energy Rev 2011; 15: 3278-3300.

26. Bonatesta F, Chiappetta E, La Rocca A. Part-load particulate matter from a GDI engine and the connection with combustion characteristics. Appl Energy 2014; 124: 366-376.

27. Reijnders J, Boot M, de Goey P. Particle nucleation-accumulation mode trade-off: A second diesel dilemma? $J$ Aerosol Sci 2018; 124: 95-111.

28. Überall A, Otte R, Eilts P, et al. A literature research about particle emissions from engines with direct gasoline injection and the potential to reduce these emissions. Fuel 2015; 147: 203-207. 
29. Seinfeld JH, Pandis SN. Atmospheric chemistry and physics : from air pollution to climate change. 2nd ed. Hoboken, New Jersey: John Wiley \& Sons, 2006.

30. Benajes JV, López JJ, Novella R, et al. ADVANCED METHODOLOGY FOR IMPROVING TESTING EFFICIENCY IN A SINGLE-CYLINDER RESEARCH DIESEL ENGINE. Exp Tech 2008; 32: 41-47.

31. Nazemi M, Shahbakhti M. Modeling and analysis of fuel injection parameters for combustion and performance of an RCCI engine. Appl Energy 2016; 165: 135-150.

32. Jain A, Singh AP, Agarwal AK. Effect of fuel injection parameters on combustion stability and emissions of a mineral diesel fueled partially premixed charge compression ignition (PCCI) engine. Appl Energy 2017; 190: 658-669.

33. Brückner C, Pandurangi SS, Kyrtatos P, et al. NOx emissions in direct injection diesel engines - part 1: Development of a phenomenological NOx model using experiments and three-dimensional computational fluid dynamics. Int J Engine Res 2018; 19: 308-328.

34. Desantes JM, Benajes J, García A, et al. The role of the in-cylinder gas temperature and oxygen concentration over low load reactivity controlled compression ignition combustion efficiency. Energy 2014; 78: 854-868.

35. Schneider J, N. Hock, S. Weimer A, et al. Nucleation Particles in Diesel Exhaust: Composition Inferred from In Situ Mass Spectrometric Analysis. Environ Sci Technol 2005; 39: 6153-6161.

36. Zhang Y, Ghandhi J, Rothamer D. Comparisons of particle size distribution from conventional and advanced compression ignition combustion strategies. Int J Engine Res 2018; 19: 699-717.

37. Kosaka H, Aizawa T, Kamimoto T. Two-dimensional imaging of ignition and soot formation processes in a diesel flame. Int J Engine Res 2005; 6: 21-42.

38. Corcione FE, Merola SS, Vaglieco BM. Evaluation of temporal and spatial distribution of nanometric particles in a diesel engine by broadband optical techniques. Int J Engine Res 2002; 3: 93-101.

39. Li X, Guan C, Luo Y, et al. Effect of multiple-injection strategies on diesel engine exhaust particle size and nanostructure. J Aerosol Sci 2015; 89: 69-76.

40. Musculus MP, Dec JE, Tree DR. Effects of Fuel Parameters and Diffusion Flame Lift-Off on Soot Formation in a Heavy-Duty DI Diesel Engine. In: SAE Technical Paper, 2002-01-0889. DOI: 10.4271/2002-01-0889.

41. Seong HJ, Boehman AL. Studies of soot oxidative reactivity using a diffusion flame burner. Combust Flame 2012; 159: 1864-1875.

42. Desantes JM, Bermúdez V, García A, et al. A Comprehensive Study of Particle Size Distributions with the Use of PostInjection Strategies in DI Diesel Engines. Aerosol Sci Technol 2011; 45: 1161-1175.

43. Pickett LM, Siebers DL. Soot in diesel fuel jets: effects of ambient temperature, ambient density, and injection pressure. Combust Flame 2004; 138: 114-135.

44. Matthias N, Farron C, Foster DE, et al. Particulate Matter Sampling and Volatile Organic Compound Removal for Characterization of Spark Ignited Direct Injection Engine Emissions. SAE Int J Fuels Lubr 2011; 5: 2011-012100 .

\section{Definitions/Abbreviations}

aTDC after top dead center

CA10 crank angle for $10 \%$ of fuel burnt

CA50 crank angle for $50 \%$ of fuel burnt

CA90 crank angle for $90 \%$ of fuel burnt

CA90-CA10 combustion duration

CDC conventional diesel combustion

CI compression-ignition

DMDF dual-mode dual-fuel

$\mathrm{dN}$ number concentration

$\mathrm{dP} / \mathrm{d} \alpha_{\max } \quad$ pressure gradient

EGR exhaust gas recirculation

EoI end of fuel injection

GF gasoline fraction

HCCI homogeneous charge compression ignition

ICE internal combustion engine

IMEP indicated mean effective pressure
IP injection pressure

LTC low temperature combustion

Mix. Time diesel mixing time

$m_{\text {fuel }}$ fuel mass flow

PFI port fuel injection

PPC partially premixed combustion

PM particulate matter

$\mathrm{P}_{\max }$ peak cylinder pressure

PSD particle size distribution

RON research octane number

RoHR rate of heat release

RCCI reactivity controlled compression ignition

SOI start of the injection

SoC start of combustion 
Figure 1. Scheme of the test bench.

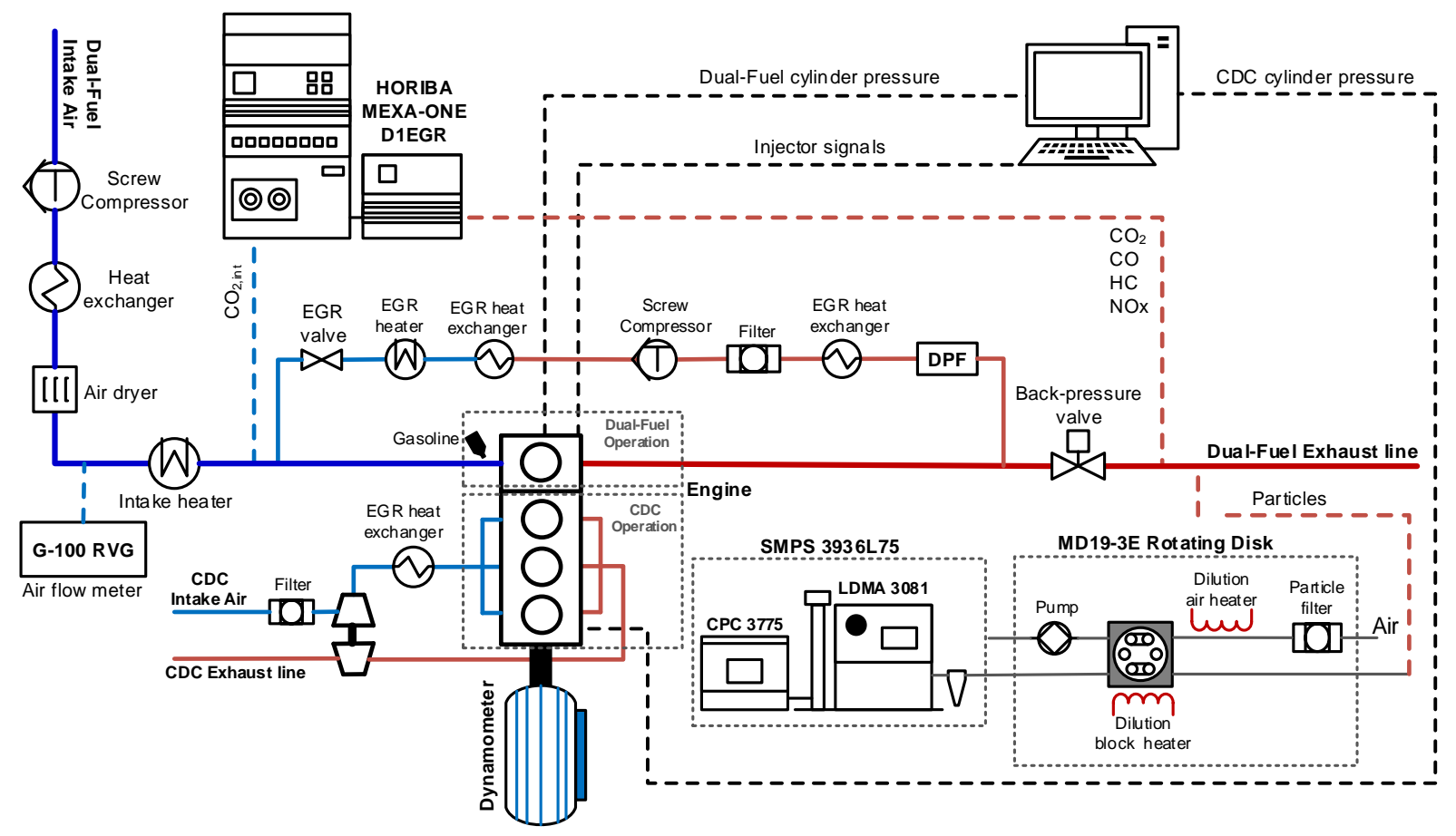

Figure 2. Gasoline fraction (GF) rate maps used to implement the DMDF strategy.

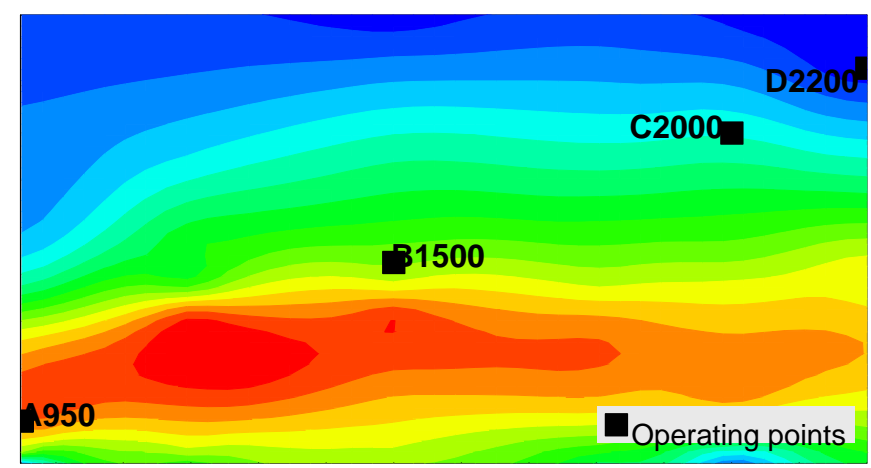


Figure 3. Effect of diesel main injection timing (SOImain) on the cylinder pressure and RoHR profile at each operating point: (a) Fully premixed RCCI, (b) Highly premixed RCCI and (c)-(d) Dual-fuel diffusion.
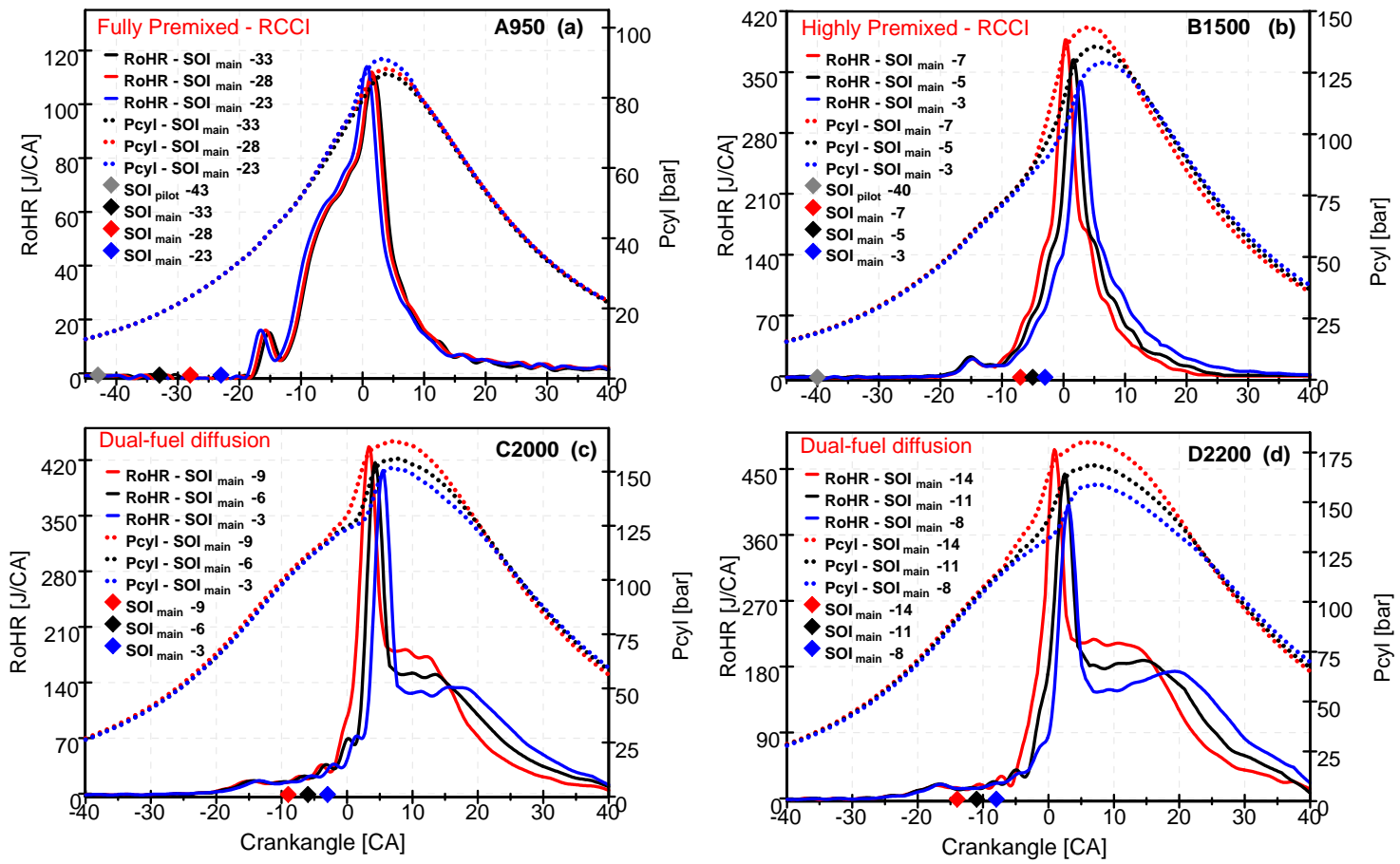

Figure 4. Effect of SOImain on combustion phase (CA10 and CA50), dP/damax, Pmax, CA90-CA10 and Mixing Time, at each operating point: (a)-(a.2) Fully premixed RCCI, (b)-(b.2) Highly premixed RCCI, (c)(c.2) and (d)-(d.2) Dual-fuel diffusion.
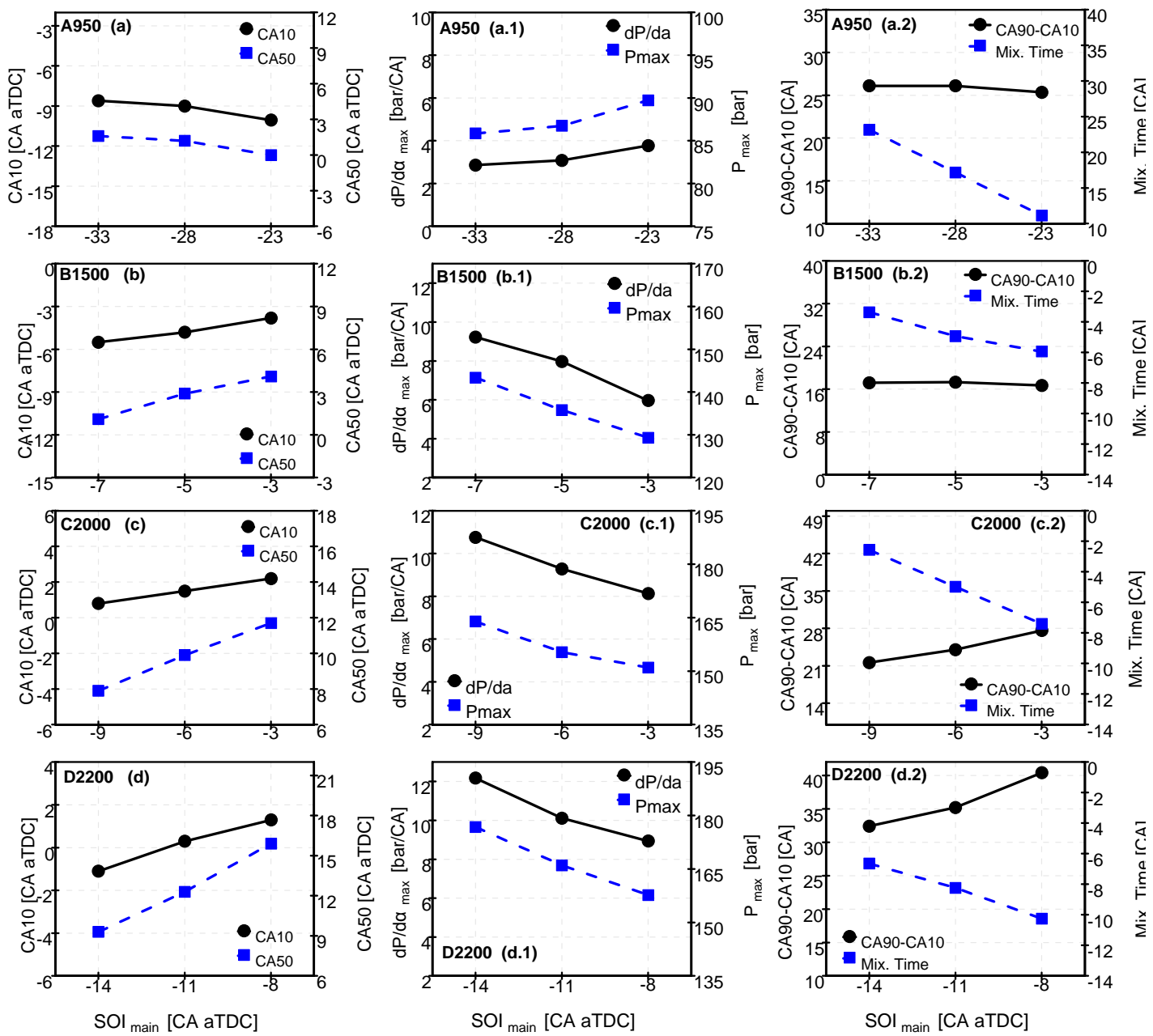
Figure 5. Effect of SOImain on gaseous compounds emissions (HC, CO and NOx), at each operating point: (a)(a.2) Fully premixed RCCI, (b)-(b.2) Highly premixed RCCI, (c)-(c.2) and (d)-(d.2) Dual-fuel diffusion.
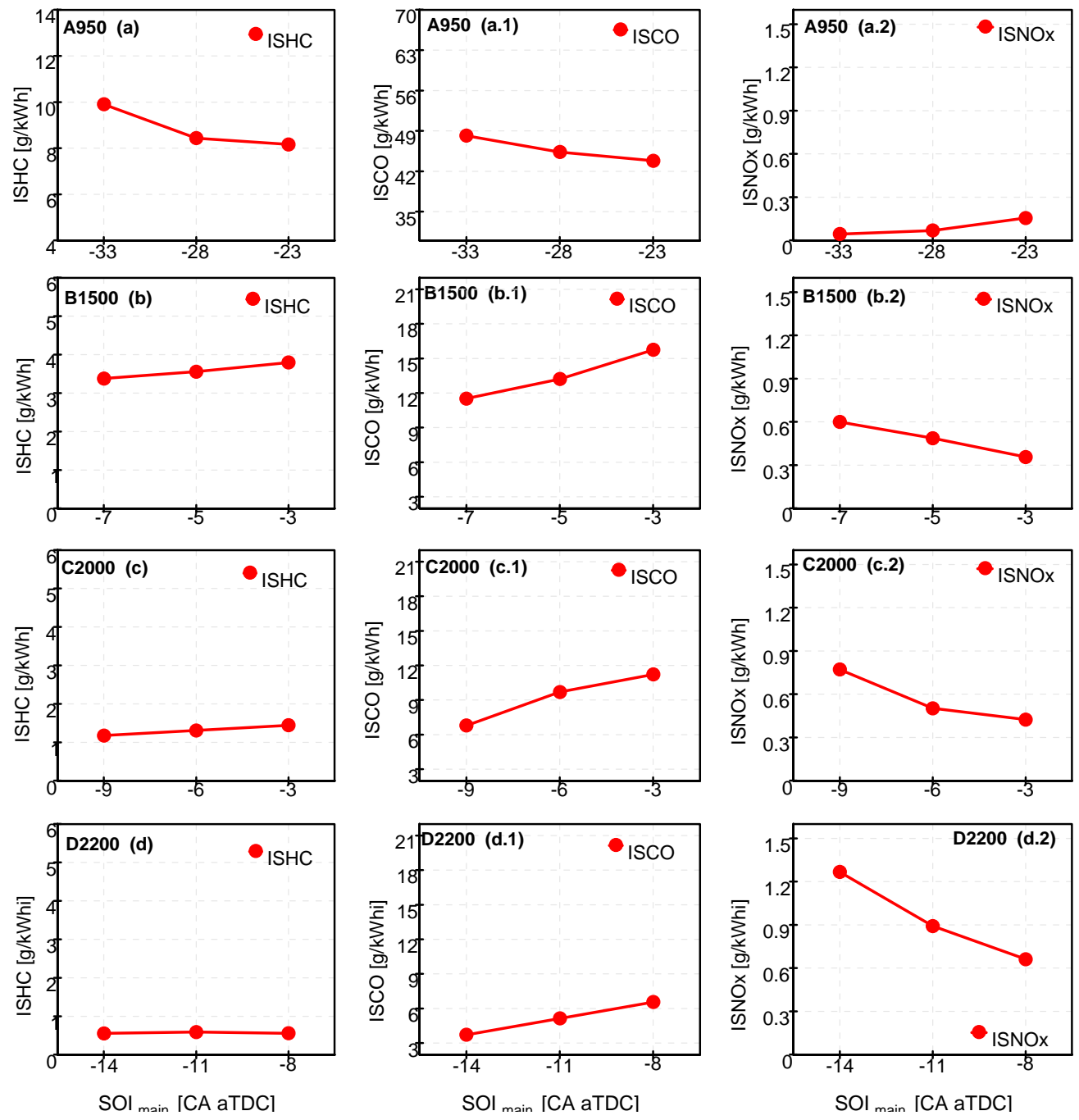
Figure 6. Effect of SOImain on the PSD and PN emissions, at each operating point: (a)-(a.1) Fully premixed RCCI, (b)-(b.1) Highly premixed RCCI, (c)-(c.1) and (d)-(d.1) Dual-fuel diffusion.
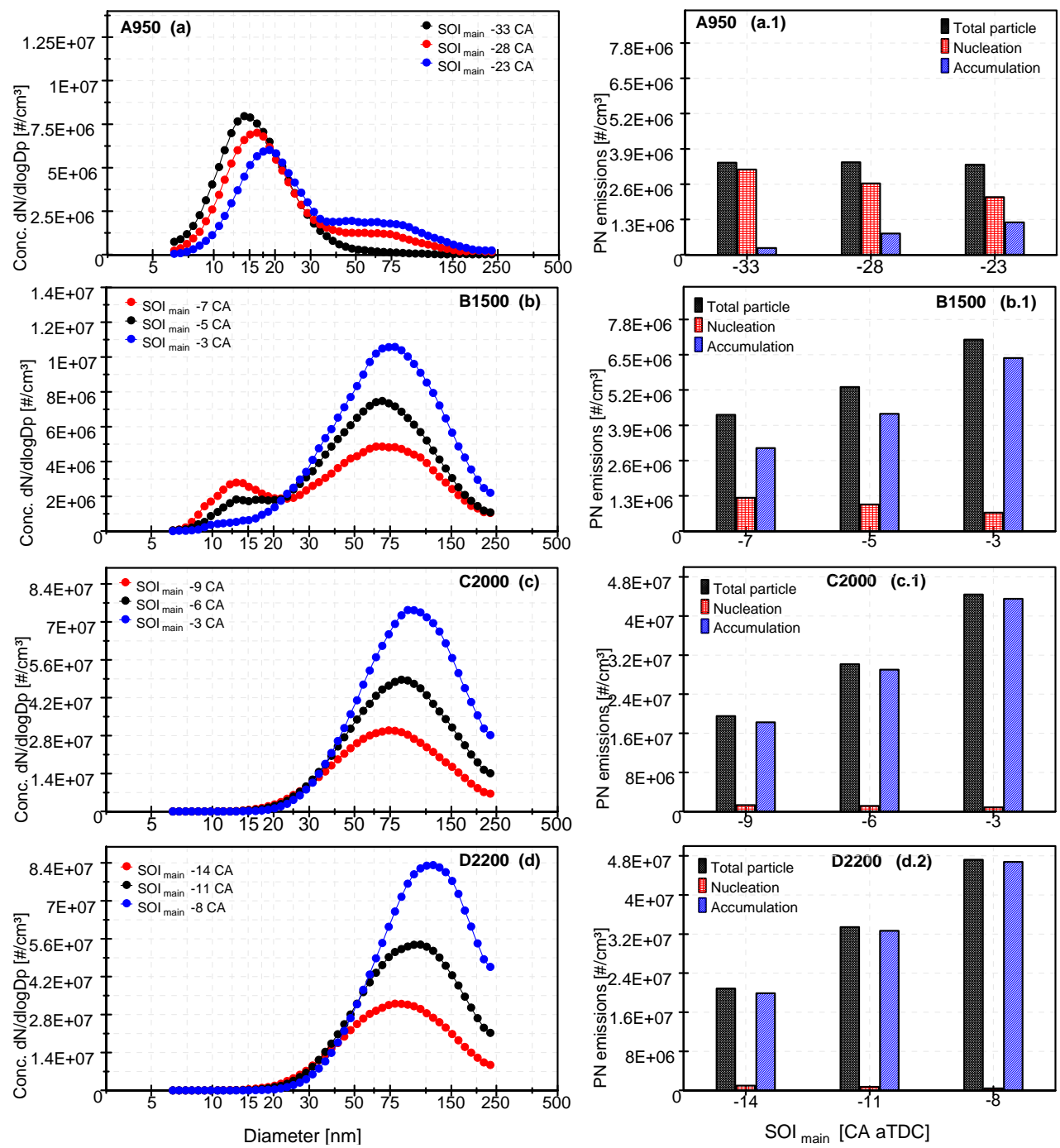
Figure 7. Effect of injection pressure (IP) on the cylinder pressure and RoHR profile at each operating point: (a) Fully premixed RCCI, (b) Highly premixed RCCI and (c)-(d) Dual-fuel diffusion.
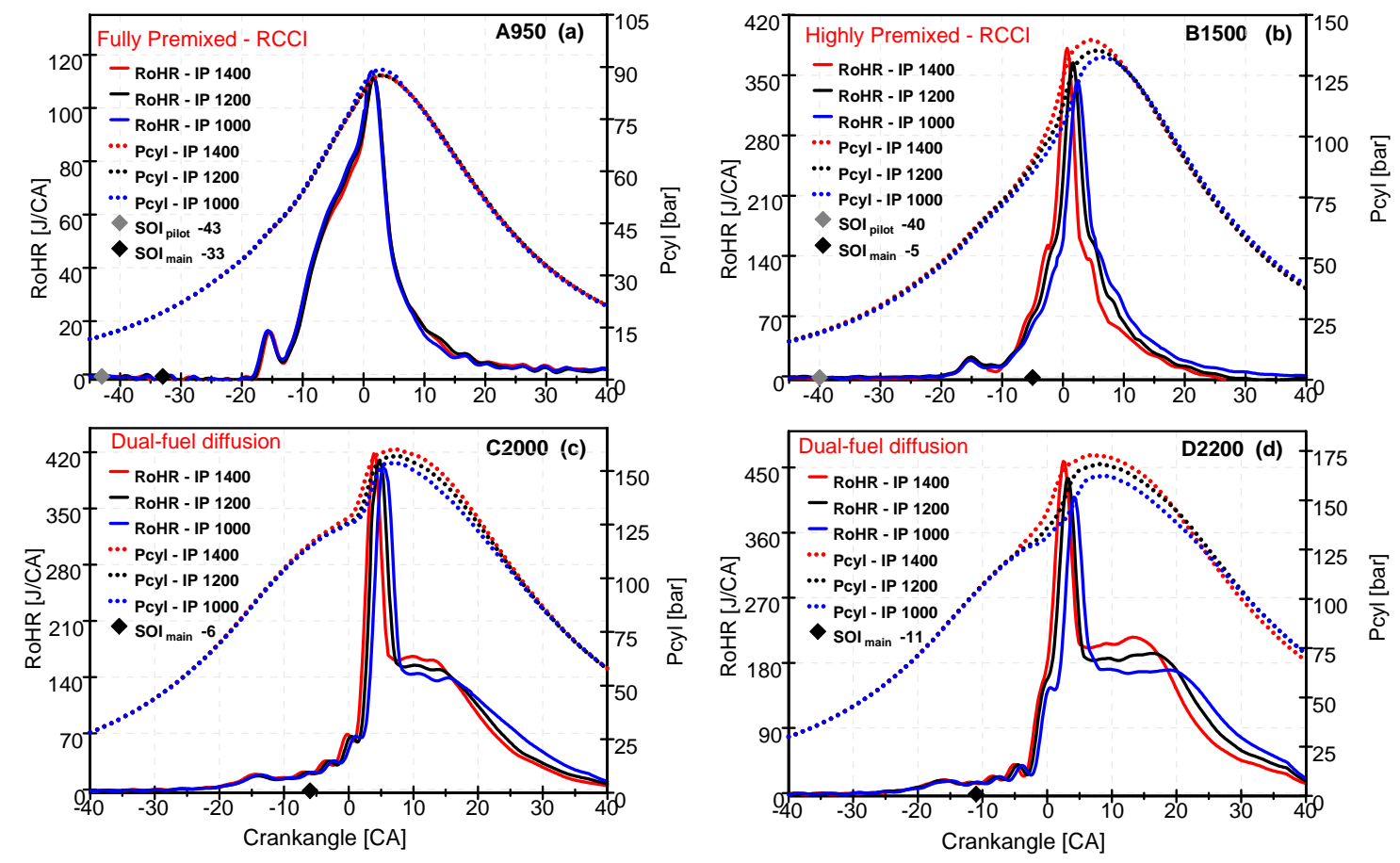

Figure 8. Effect of IP over combustion phase (CA10 and CA50), dP/d $\alpha$ max, Pmax, CA90-CA10 and Mixing Time, at each operating point: (a)-(a.2) Fully premixed RCCI, (b)-(b.2) Highly premixed RCCI, (c)-(c.2) and (d)-(d.2) Dual-fuel diffusion.
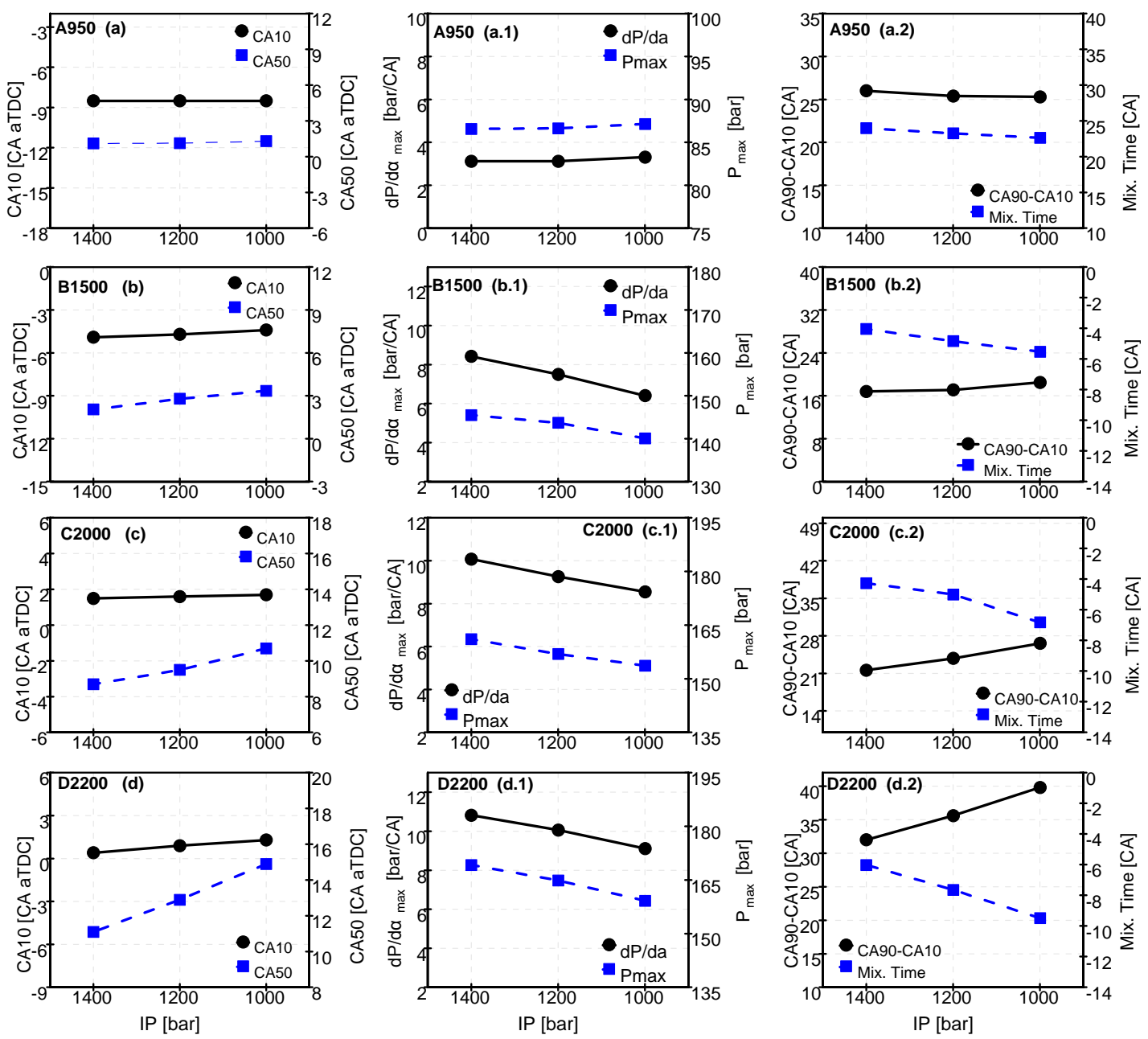
Figure 9. Effect of IP on gaseous compounds emissions (HC, CO and NOx), at each operating point: (a)-(a.2) Fully premixed RCCI, (b)-(b.2) Highly premixed RCCI, (c)-(c.2) and (d)-(d.2) Dual-fuel diffusion.
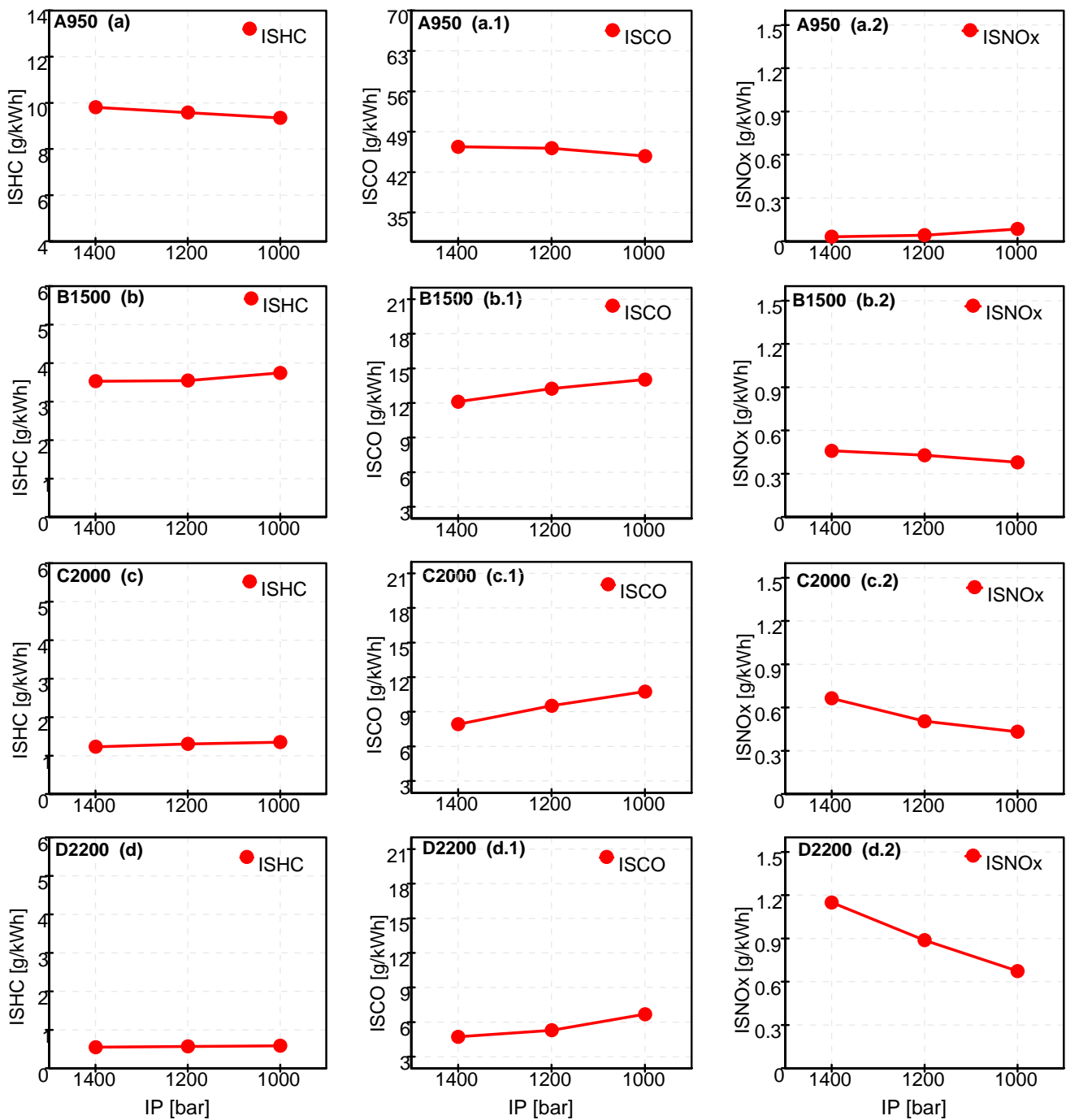
Figure 10. Effect of IP on the PSD and PN emissions, at each operating point: (a)-(a.1) Fully premixed RCCI, (b)-(b.1) Highly premixed RCCI, (c)-(c.1) and (d)-(d.1) Dual-fuel diffusion.
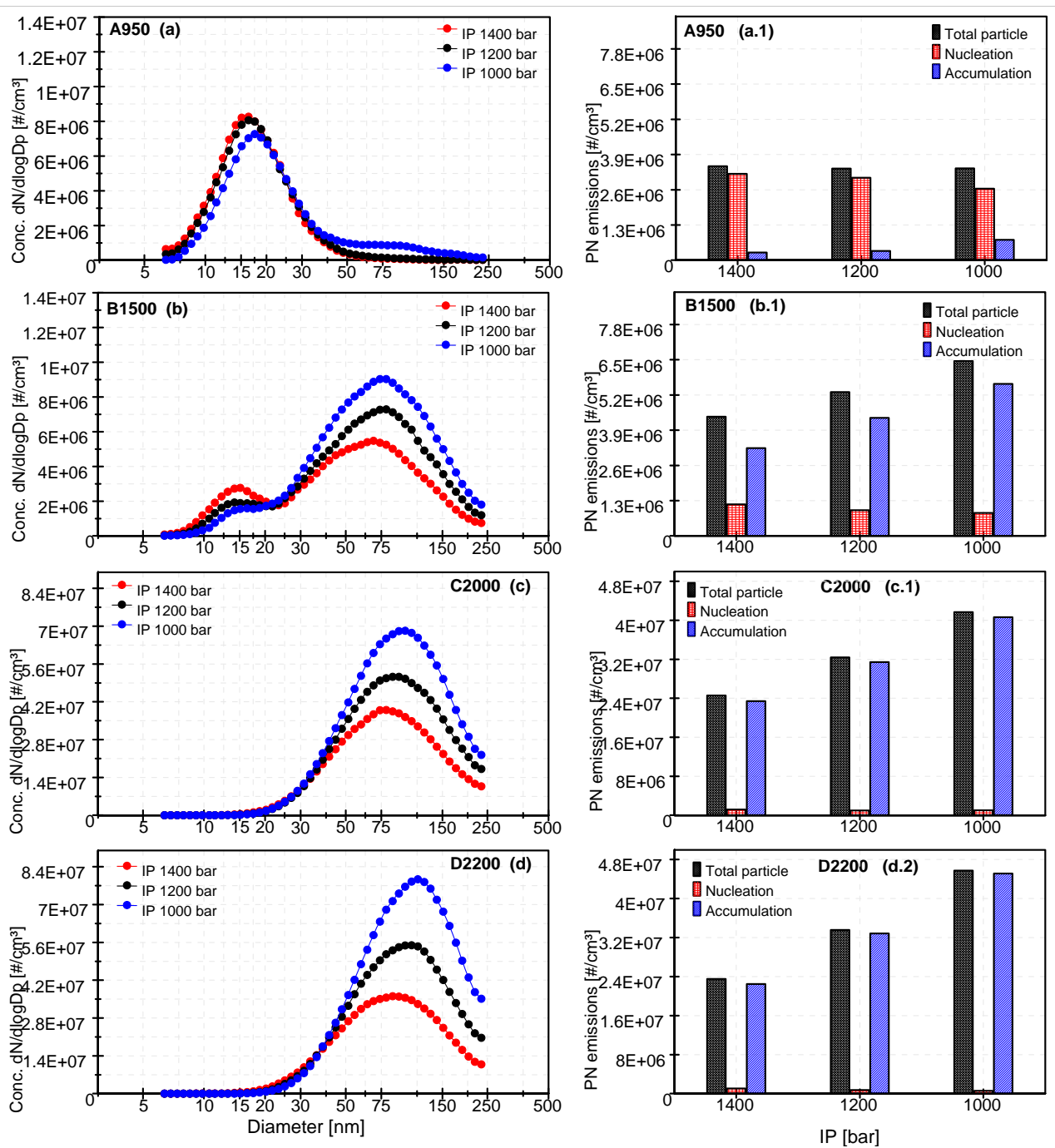